\title{
A metáfora das abelhas em Columela: guerra e diplomacia sob Nero*
}

\author{
The metaphor of the bees in Columella: war and diplomacy \\ under Nero
}

Helton Lourenço Carvalho**

\begin{abstract}
Resumo: A apicultura nas sociedades antigas, além de compor o quadro econômico e produtivo, integrava também o repertório literário, que, por meio de uma linguagem alegórico-metafórica, refletia sobre as relações de poder e os modelos de governo que uma parcela da aristocracia letrada postulava como ideal. Nesse sentido, o objetivo deste artigo será o de compreender parte das prescrições do livro nono do De Re Rustica como sendo uma metáfora que reflete sobre as tensões envolvendo o imperador, Senado e o exército, sobretudo, com relação aos desdobramentos dos conflitos na fronteira oriental durante o principado de Nero.
\end{abstract}

\begin{abstract}
Beekeeping in ancient societies, in addition to composing the economic and productive framework, also integrated the literary repertoire that through an allegorical-metaphorical language reflected on power relations and government models that a portion of the literate aristocracy postulated as being the ideal one. In this sense, the objective of this article will be to understand part of the prescriptions of the ninth book of De Re Rustica as being a metaphor that reflects on the tensions involving the Emperor, Senate and the Army, especially with regard to the conflicts on the eastern border during the Nero's Principate.
\end{abstract}

Palavras-chave:

Poder.

Abelhas.

Metáfora.

Columella.

\section{Keywords: \\ Power. \\ Bees. \\ Metaphor. \\ Columella.}

\footnotetext{
* O presente trabalho foi realizado com apoio da Coordenação de Aperfeiçoamento de Pessoal de Nível Superior (Capes), código de financiamento 001.

** Doutorando em História pelo Programa de Pós-Graduação da Universidade Federal de Ouro Preto (Ufop), sob orientação do Prof. Dr. Fábio Duarte Joly. É membro do Laboratório de Estudos sobre o Império Romano (Leir/Ufop).
} 


\section{Introdução}

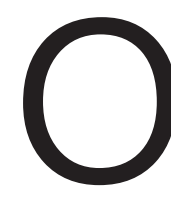

De Re Rustica, de Columela, foi escrito no século I, durante o principado de Nero. Em conjunto com os tratados agrícolas de Catão e Varrão, compõe o que se convencionou denominar de "tratados agronômicos latinos". Embora separados cronologicamente, entre os dois últimos séculos da República e o primeiro do Principado, na moderna historiografia estes tratados foram analisados em conjunto e com um interesse predominantemente voltado para os estudos da economia antiga. No entanto, em alguns estudos mais recentes percebe-se um deslocamento da abordagem economicista para outra, voltada em compreender os aspectos retóricos, políticos e ideológicos presentes nestas obras. ${ }^{1}$ Para esta abordagem, além de evidenciar um sistema produtivo, tais prescrições atuavam como uma autorrepresentação política e ideológica de uma parcela da aristocracia, que, por meio desta literatura, idealizava o que seria mais ou menos compatível com a ideologia moral aristocrática romana. ${ }^{2}$

No caso específico de Columela, por exemplo, Fábio Joly defendeu a hipótese de que, ao se debruçar sobre a organização da uilla, o autor é influenciado por um panorama mais amplo e centrado no sistema organizacional da res publica. Para Joly, além dos interesses econômicos, os aspectos políticos são referenciais importantes em sua projeção da organização e distribuição dos espaços internos da uilla. Com isso, ele aponta que, no processo de transição entre a República e o Principado, devido à crescente concentração de poder nas mãos dos imperadores nos espaços públicos, a aristocracia procurava restabelecer o seu poder no espaço privado, e "daí as comparações domus e res publica que, no caso de Columela, leva-o a desenhar a uilla ideal como um pequeno Estado, em cujo topo está o proprietário na figura de um 'imperador'" (JOLY, 2003, p. 282). Tal projeção, ainda segundo Joly (2003, p. 296), emergia em decorrência da preocupação da literatura da época em formular uma nova ética de participação política para apresentar ao imperador modelos de conduta que tinham como parâmetros figuras de autoridade como pater e dominus.

Como observa Fábio Faversani (2015, p. 43-4), "as disputas entre os aristocratas, no interior das quais se coloca a produção literária, teriam suas condições de realização dramaticamente modificadas com o Principado". Nesse sentido, o uso de figuras de linguagem era uma estratégia retórica importante, que permitia à aristocracia letrada empreender um discurso ou uma obra que circulasse no ambiente político, mas que não

\footnotetext{
${ }^{1}$ Ver, por exemplo: Kronenberg (2009), Reay (2011, p. 61-68) e Nelsestuen (2015).

2 Para um balanço destas diferentes abordagens, ver: Knust (2017).
} 
ferisse nem o imperador, nem os demais aristocratas. Isto porque, para a sustentação de uma postura de confronto aberto, tal indivíduo dependia de uma rede de relações interpessoais, que, em última instância, dependia ou da figura do imperador ou dos demais aristocratas. Esta é, por exemplo, a opinião de Dylan Sailor (2008, p. 49), que alega que, durante o Principado, os aristocratas atuavam em "um estado constante e permanente de dívida para com o princeps, uma situação repleta de perigos para a estimativa de uma audiência e a independência de um texto". Ainda nas palavras de Faversani (2015, p. 45):

Isto coloca um paradoxo importante ao principado. Se o é por definição o mais valoroso dos aristocratas, caso um aristocrata mostre valor invulgar e passe a ser reconhecido pelos demais, este aristocrata poderá facilmente ser tomado como alguém que aspira à posição imperial. Deste modo, tem-se um movimento duplo. Por um lado, os imperadores serão acusados de não reconhecer aristocratas valorosos, por temê-los. Por outro lado, os próprios aristocratas evitarão a exposição excessiva de seus talentos e evitarão um reconhecimento por demais ruidoso de seu valor.

Considerando este contexto de produção literária, o presente artigo terá como pressuposto esta ampliação de horizonte interpretativo do texto de Columela, para além dos aspectos meramente econômicos. Para tanto, abordaremos a temática da gestão das abelhas, presente no livro IX do De Re Rustica, como uma metáfora que reflete as tensões entre o imperador, ${ }^{3}$ o Senado e o exército a respeito das ações desenvolvidas durante os conflitos com o Império Parto à época de Nero.

Desta forma, embora tal propósito privilegie os aspectos ideológicos e políticos por meio da análise da retórica de Columela, ressaltamos que de modo algum defendemos que a sua abordagem da temática das abelhas esteja totalmente apartada de um referencial material concreto. Pelo contrário, ao nosso ver, é por meio desta realidade que Columela elabora seus argumentos para níveis mais amplos do que aqueles circunscritos à uilla. Além disso, a experiência militar de Columela no Oriente como tribuno militar é comumente negligenciada. ${ }^{4}$ Mas, a nosso ver, isso reflete na forma como ele percebia o universo das abelhas, sobretudo, devido à utilização de um vocabulário notadamente de caráter militar. ${ }^{5}$ Por fim, o fato de Columela tornar o saber agrícola em objeto literário

\footnotetext{
${ }^{3}$ Como não é nossa intenção discutir o uso deste tropo linguístico, limitamos a indicar o nosso referencial para a utilização deste recurso hermenêutico: Lakoff (1980), Joly (2004).

${ }^{4}$ De acordo com Harrison Ash (1960, p. xv), uma inscrição encontrada na cidade de Tarento que indica sua presença na Síria como tribuno militar: "L. IVNIO L. GAL. MODERATO COLVMELLAE TRIB. MIL. LEG VI FERRATAE" (CIL IX 235 (= Dessau 2932); "Lúcio Júnio L. Gal. Moderato Columella Tribuno Militar da Legião VI Ferrata", tradução minha).

${ }^{5} \mathrm{O}$ vocabulário militar também é empregado em suas prescrições sobre a gestão da escravidão. O dominus é comparado a um imperator enquanto uilicus a um dux. Para Fábio Joly (2003, p. 291-292), no caso da escravidão, "embora, em um plano estritamente administrativo, a metáfora seja válida - mesmo porque Columela serviu como legado em legiões na Síria - , a questão do poder na uilla descrita por Columela não se resume à transposição de uma hierarquia militar
} 
demonstra o seu interesse em se inserir em debates mais amplos que não estavam restritos apenas à utilização meramente instrumental, ou seja, de conferir preceitos sobre a prática de criação de animais na villa.

Dessa forma, acreditamos que a explicitação da metáfora das abelhas no texto de Columela corrobora esta perspectiva, que valoriza também os aspectos políticos e ideológicos, embora ainda pouco convencional, mas que nos permite dilatar as possibilidades de significados do De Re Rustica.

O artigo será dividido em três partes. Na primeira parte, trataremos da temática das abelhas como uma metáfora política presente em diversos momentos e autores da Antiguidade Clássica. Na segunda, o objetivo será abordar especificamente a metáfora das abelhas no texto de Columela. Por fim, na última sessão do artigo, pretendemos relacionar a metáfora das abelhas com os conflitos no Oriente, isto é, as disputas entre romanos e partos pela dominação da Armênia à época do principado de Nero.

\section{As abelhas como uma metáfora política na Antiguidade Clássica}

A apicultura é uma atividade produtiva que esteve presente em diversas sociedades da Antiguidade. Contudo, as sistematizações das prescrições sobre esta modalidade de criação encontram-se dispersas na tradição que precede as sociedades greco-romanas. Nas sociedades pré-capitalistas, a criação de abelhas era parte integrante do universo produtivo. Varrão (De Re Rustica, 3, 16, 10-12), por exemplo, nos informa através de um dos personagens de seu tratado, Mérula, que dois irmãos, ambos militares, em uma pequena fazenda herdada do pai, costumavam obter com a produção de mel uma estimativa de dez mil sestércios por safra.

Para além do interesse econômico, a apicultura também integrava a esfera cultural dessas sociedades. A observação das abelhas e da organização interna das colmeias atuava de forma alegórica-metafórica como um parâmetro de comparação com a sociedade humana.

Esta relação alegórico-metafórica se projetava, sobretudo, como forma de elucidar os princípios que as aristocracias letradas das sociedades mediterrânicas qualificavam como sendo o ideal de administração e organização da sociedade e as qualidades necessárias para um governante virtuoso. Obviamente, estas ideias mudavam de acordo

para a diferenciação dos trabalhadores agrícolas. A nosso ver, e será este o ponto abordado doravante, o tratado de Columela incorpora debates políticos mais amplos que tinham lugar no principado neroniano e cujo tema principal era a autoridade imperial e seu modo de se postar diante da aristocracia. Não por acaso o problema da legitimação do poder é central para a reflexão de Columela sobre os papéis do uilicus e do proprietário". 
com os contextos e interesses das aristocracias, que não partilhavam de apenas um modelo ideal de gestão da sociedade ou de príncipe ideal. Como sintetiza Sam Van Overmeire (2011, p. 32-33):

\begin{abstract}
Gregos e romanos tinham suas visões próprias, e de alguma forma, únicas sobre o governo, sobre os governantes "legítimos" e suas virtudes primárias. Várias dessas ideias foram difundidas no mundo mediterrâneo, e aqui é essencial notar que alguma visão de um rei perfeito, um autocrata apto a governar por suas virtudes, pode ser encontrada entre autores gregos e romanos de todos os períodos. Muitas outras ideias e conceitos dependiam da situação histórica específica. Os autores gregos do século $V$ a.C. escreveram muito sobre a pólis (cidade-estado) e a democracia, enquanto os tratados sobre a realeza ideal tornaram-se onipresentes na era helenística. Os pensadores republicanos romanos enfatizavam a excelência de seu governo e, durante o Principado, a maioria dos filósofos se voltava para as virtudes do soberano. É bem possível que as ideias políticas, especialmente as que dizem respeito aos autocratas, influenciaram a aparência do rei das abelhas na literatura. Como a colmeia, eles ofereceram uma metáfora interessante para a sociedade humana.
\end{abstract}

Para Aristóteles (Historia Animalium, 1, 488a), por exemplo, a organização das abelhas se assemelha a dos humanos, sobretudo pelo fato de elas obedecerem a um chefe, diferentemente, por exemplo, das formigas, em que a figura de um líder é ausente. Esta comparação entre o príncipe ideal e o chefe das abelhas se torna ainda mais perceptível em Platão e Sêneca. Platão, no livro sétimo da República, descreve que, ao abordar a educação ideal dos governantes através da alegoria da caverna, Sócrates responde a Glauco que os governantes, depois de educados tal como os filósofos, serão capazes de governar tal como os chefes e o rei das abelhas. Em seu tratado Sobre a Clemência dirigido ao imperador Nero, Sêneca articula esta comparação assim:

Decerto foi a natureza que inventou o rei, fato que se pode observar a partir dos outros animais, e entre eles, as abelhas, cujo rei tem o alvéolo mais espaçoso e colocado no centro e no lugar mais seguro. Além disso, desobrigado de trabalhar, é o supervisor dos trabalhadores e dos demais, e, tendo se perdido o rei, todo o enxame se dispersa, não toleram mais do que um só rei e procuram o melhor em combate (Sêneca, De Clementia, 1, 19, 2, tradução de Ingeborg Braren).

Enquanto, para Sócrates, o rei se destaca por sua superioridade devido ao conhecimento obtido junto aos filósofos, para Sêneca, o monarca se destaca por sua capacidade de ser clemente com seus subordinados. Ademais, a sua presença é requisitada como mediador dos conflitos societários. E, assim como entre as abelhas os chefes se distinguem por seu tamanho ou cor, para Platão e Sêneca o príncipe ideal também se distingue dos demais ao agir como um sábio (filósofo). 
Na literatura agrária latina, a metáfora também é bastante recorrente. Mérula, um dos interlocutores do diálogo de Varrão, Sobre as Coisas do Campo, relata que as colmeias "são como as cidades dos homens, pois aqui há um rei, império e sociedade" e que todas as abelhas "vivem como no exército, dormem e trabalham igualmente em turnos; também enviam como que colônias, e seus chefes dão certas ordens com a voz como se imitassem uma trombeta" (Varrão, De re rustica., 3, 16, 8-9). ${ }^{6}$ Da mesma forma, Virgílio (Georgicon, 4, 153-155) alega que "apenas as abelhas têm filhos em comum e em sua cidade, casas indivisas e passam suas vidas sujeitas a grandes leis, e, somente elas reconhecem uma pátria e Penates imutáveis". Também Plínio, o Velho, compara a organização da colmeia de forma semelhante àquela da sociedade civil. Ele argumenta que, quando coexistem vários reis, a decisão de matar os piores deve ser votada entre os pares: "Começam criando vários reis, para que não falte. Então, dentre eles, quando estão adultos, com a unanimidade dos votos (concordis suffragium), eles matam o pior para que o enxame não seja dividido" (Plínio, Naturalis Historia, 11, 16, 50-51). ${ }^{8}$ Plínio coloca as abelhas como um exemplo a ser seguido da seguinte forma:

Recolhem mel e um suco doce, leve e salubre, fazem favos e cera para mil usos da vida, suportam o trabalho, cumprem sua tarefa, têm sua República, também tomam decisões em particular, mas têm seus generais em comum, e o que é acima de tudo incrível, costumes diferentes uns dos outros, não sendo animais domésticos ou selvagens. A natureza é tão grande que, mesmo com a menor sombra de um animal, realiza feitos incomparáveis. Que estímulos, que forças podemos comparar a uma eficiência tão grande? Que homens, eu pergunto, podemos classificar em racionalidade com esses insetos, que inquestionavelmente superam a humanidade nisso, quem como elas reconhecem apenas o interesse comum? (Plin., HN., 11, 4, 11-12). ${ }^{9}$

\footnotetext{
${ }^{6}$ No original: Haec ut hominum ciuitates, quod hic est et rex et imperium et societas; Omnes ut in exercitu uiuunt atque alteris dorminunt et opus faciunt pariter et ut colônias mittunt, ïque duces conficiunt quaedam ad uocem ut imitione tubae. ${ }^{7}$ No original: Solae communes natos, consortia tecta / urbis habent magnisque agitant sub legibus aevum, / et patriam solae et certos novere penates. Doravante, com exceção dos tradutores indicados, todas as traduções são de minha autoria.

${ }^{8}$ No original: reges plures inchoantur, ne desint; postea ex his suboles cum adulta esse coepit, concorde suffragio deterrimos necant, ne distrahant agmina. duo autem genera eorum, mehor rufus, deterior niger variusque. Sobre esta passagem de Plínio, Sam Van Overmeire (2011, p. 42) diz o seguinte: "As ideias contemporâneas do papel dos príncipes romanos são óbvias: enquanto governam de forma suprema, ainda servem ao povo e são - ou deveriam ser - escolhidos pelo reconhecimento da cúria (Senado). Plínio era um senador e, assim, imaginou um grupo de pares (iguais, isto é, senadores) e lictores acompanhando os reis. Era importante para Plínio mostrar que mesmo esses reis naturais, literalmente nascidos para a tarefa em mãos e de posse de todos os símbolos da realeza, ainda precisassem da ajuda de seus iguais e do apoio do povo."

${ }^{9}$ No original: mella contrahunt sucumque dulcissimum atque subtilissimum ac saluberrimum, favos confingunt et ceras mille ad usus vitae, laborem tolerant, opera conficiunt, rem publicam habent, consilia privatim quoque, at duces gregatim et, quod maxime mirum sit, mores habent praeter cetera, cum sint neque mansueti generis neque feri. tanta est natura rerum, ut prope ex umbra minima animalis incomparabile effecerit quiddam. quos efficaciae industriaeque tantae comparemus nervos, quas vires quos ratione medius fidius iis viros, hoc certe praestantioribus quod nihil novere nisi comune?
} 
Como podemos perceber, a partir dos trechos acima selecionados, a projeção da organização da colmeia como uma representação da sociedade humana é explícita para estes autores. Para Varrão, sua organização se assemelha a um acampamento militar, elas formam colônias e obedecem a um rei. Virgílio acrescenta que elas obedecem a leis (leges), formam uma comunidade e veneram os deuses domésticos (penates) como os humanos. Enquanto que, para Plínio, o Velho, sua organização é semelhante a uma República (res publica), com seus conselhos privados (concilia privati), generais (duces), sendo consideradas igualmente ou até mesmo superiores em racionalidade com relação aos humanos. Como observa Sam Van Overmeire (2011, p. 33):

Ao olhar para o antigo retrato das abelhas, devemos considerar a maneira como este processo poderia funcionar em duas direções: enquanto a organização desses insetos poderia ser compreendida usando conceitos humanos, eles também ajudaram a tornar a ordem social compreensível, e a sua cooperação foi também um exemplo natural que a humanidade poderia seguir.

Em direção semelhante, Neville Morley (2007, p. 462) aponta que "não apenas as discussões filosóficas, mas também a literatura mais técnica sobre a apicultura é influenciada tanto pelo contexto político e preocupações dos membros da elite romana como pela experiência prática e pela tradição científica." Este mesmo autor ainda ressalta que:

\footnotetext{
O que chama a atenção nos relatos romanos sobre as abelhas é a maneira como foram influenciados não só pela mitologia, tradição literária e autoridade de Aristóteles, mas também por preocupações políticas contemporâneas. As fontes tendem a interpretar todo o comportamento das abelhas não apenas em termos humanos, mas em termos especificamente romanos, e assumir a existência de toda uma gama de instituições romanas dentro da colmeia (MORLEY, 2007, p. 462).
}

Dessa forma, a atenção conferida a estes animais, para a explicação da ordenação societária, não deve ser compreendida apenas como uma abstração dos aspectos técnicos ou dos recursos econômicos que poderiam ser obtidos através de sua criação. Pelo contrário, era a observação concreta da organização comunitária destes animais que possibilitava uma comparação destes animais com a sociedade humana. Ademais, Neville Morley nos chama a atenção para um elemento importante. Embora o uso alegórico-metafórico seja compartilhado por diferentes culturas literárias, este recurso é acompanhado de contornos próprios, relativos à conjuntura sociopolítica e econômica em que estão inseridos. Na literatura latina, "a colmeia era vista como um microcosmo de Roma e seu comportamento interpretado em termos de preocupações políticas contemporâneas, e que, por sua vez, influenciava as práticas da apicultura romana" (MORLEY, 2007, p. 462). 
Considerando os breves exemplos acima aventados, a seguir centraremos nossa atenção nas prescrições de Columela acerca do universo das abelhas. O objetivo será evidenciar como tais prescrições também refletem relações e tensões de poder em níveis mais amplos, envolvendo o imperador, o exército e o Senado.

\section{As abelhas e suas metáforas em Columela}

O cuidado com as abelhas está situado no livro nono do De Re Rustica, e abordado em conjunto com os preceitos sobre o tratamento dos animais selvagens, criados de forma adjacente à casa de campo. Servindo tanto ao deleite da caça, quanto ao cardápio dos banquetes, esta modalidade de criação denominada de villatica pastio compunha a paisagem de uma parcela das villae. Para Columella, a administração destes enxames requeria a presença constante do apicultor: "Pois este negócio requer a máxima honestidade, porque como ela é raríssima, a intervenção constante do senhor traz mais proteção. Neste quesito o seu responsável não deve ser fraudulento, mas pior ainda é quando ele é contaminado pela indolência e a preguiça" (Col., Rust., 9, 5, 2). ${ }^{10}$

A origem das abelhas, os tipos de abelhas, o local adequado de criação, a habitação ideal, alimentação e escolha dos enxames são alguns dos pontos destacados por Columela sobre esta modalidade de criação. Mesmo com quase um livro inteiro reservado à criação das abelhas, Columela diz que somente tratou do assunto para que sua obra não parecesse imperfeita ou mutilada, pois preceito algum poderia ser superado pela diligência de Higino, pelo ornamento de Virgílio ou pela elegância de Celso. Segundo ele, enquanto Higino compilou os ensinamentos dos antigos, Virgílio iluminou o assunto com as flores da poesia e, por fim, Celso escreveu nos dois estilos, isto é, em verso e prosa (Col., Rust., 9, 2, 1).

Embora Columela descreva alguns dos mitos de origem das abelhas, a sua opinião é de que tais assuntos interessam muito mais àqueles preocupados com os segredos da natureza, sendo, portanto, de pouca relevância para um proprietário, pois "são assuntos mais agradáveis para os estudantes de literatura que podem ler pelo prazer do que para os agricultores que são ocupados, visto que não lhes ajudam nem no trabalho ou no aumento de seus negócios" (Col., Rust., 9, 2, 5). ${ }^{11}$

\footnotetext{
${ }^{10}$ No original: Nam res ista maximam fidem desiderat, quae quoniam rarissima est, interventu domini tutius custoditur. Neque ea curatorem fraudulentum tantum sed etiam segnitiae inmundae perosa est.

${ }^{11}$ No original: Studiosis quoque litterarum gratiora sunt ista in otio legentibus, quam negotiosis agricolis, quoniam neque in opere neque in re familiari quicquam iuvant. Quare revertamur ad ea quae alveorum cultoribus magis apta sunt.
} 
A despeito do conteúdo predominantemente técnico do De Re Rustica, o seu texto não é destituído de contornos literários. Como bem destaca Matheus Trevizam, não obstante o termo "prosa técnica", o "fazer letrado antigo desconhecia qualquer tipo de corte abrupto entre, sob um aspecto, obras atinentes à 'mera' beleza expressiva e, sob outro aspecto, aquelas concentradas apenas em comunicar saberes de alguma natureza (agrários, arquitetônicos, médicos, filosóficos etc.)" (TREVIZAM, 2014, p. 188). Isso fica evidente no livro nono na utilização de uma terminologia que dialoga com uma perspectiva metafórica, comparando a colmeia a uma sociedade humana. Esta linguagem metafórica começa a ganhar relevo, sobretudo, quando ele versa sobre os cuidados desejáveis para um apicultor ideal na administração das colmeias:

\begin{abstract}
O apicultor deve ser sempre diligente, pois não há tempo em que não precise de seus cuidados, mas exige atenção ainda mais cuidadosa quando as abelhas sentem a aproximação da primavera e as colmeias transbordam com novos enxames, e se não forem capturadas pelo cuidador elas voam em diferentes direções. Pois tal é a natureza das abelhas que cada enxame de abelhas, tal como a plebe, é gerado com seu rei; quando adquirem força suficiente para voar, desprezam a sociedade de seus anciãos e ainda mais, as suas ordens. Pois, como o gênero dos mortais, que possui razão, não permite a partilha do poder real, isso ocorre igualmente entre os animais. Portanto, os novos generais emergem com o seu séquito de jovens abelhas, permanecendo por um ou dois dias na entrada da colmeia, mostrando-lhe o seu desejo de ter um domicílio próprio. Se o procurador imediatamente atribui-los, ficam tão contentes quanto em sua pátria original. Se, no entanto, o procurador estiver ausente, elas voam para uma região estranha como se tivessem sido expulsas injustamente (Col., Rust., 9, 9, 1-2). ${ }^{12}$
\end{abstract}

Como podemos perceber, o enxame das abelhas é representado por Columela como sendo a plebe (plebs) que se divide em grupos liderados por reis (reges) e generais (duces), formando legiões prontas para disputar o poder. Além disso, elas são dotadas de uma pátria (patria), de ordens (imperia), além de terem um espaço de poder reservado aos anciãos.

O apicultor é o responsável pela manutenção da ordem (imperium), mediando as tensões entre o poder representado pelos anciões da sociedade e do poder real (regnum societas), evitando assim, a dispersão da sociedade em séquitos formados por novos generais que reivindicam seus próprios domicílios.

\footnotetext{
${ }^{12}$ No original: Sed eam postulant diligentiorem cum vernant et exundant novis fetibus, qui nisi curatoris obsidio protinus excepti sunt diffugiunt. quippe talis est apium natura ut pariter quaeque plebs generetur cum regibus; qui ubi evolandi vires adepti sunt, consortia dedignantur vetustiorum, multoque magis imperia, quippe cum rationabili generi mortalium, tum magis egentibus consilii mutis animalibus nulla sit regni societas. Itaque novi duces procedunt cum sua iuventute, quae uno aut altero die in ipso domicilii vestibulo glomerata consistens, egressu suo propriae desiderium sedis ostendit, eaque tamquam patria contenta est, si procurator protinus adsignetur. Sin autem defuit custos, velut iniuria repulsa peregrinam regionem petit.
} 
Columela chama a atenção para o fato de que a divisão do poder entre os generais, além de encadear uma série de conflitos no interior da sociedade, poderia levar até mesmo à desintegração do Império. Isto porque quando o apicultor está ausente elas (as abelhas/plebe) peregrinam como se tivessem sido expulsas injustamente para outras regiões, possivelmente fora do controle do apicultor. Para tanto, ele aconselha que o apicultor deve agir da seguinte forma para evitar tais infortúnios:

Para evitar isso, é dever de um bom cuidador, na primavera, observar as colmeias até a oitava hora do dia, após o qual os novos batalhões não evadem, e cuidar diligentemente de suas saídas, pois alguns deles, como de súbito, evadem sem hesitar. Ele será capaz de descobrir antecipadamente sua decisão de escapar, colocando seu ouvido em cada uma das colmeias à tarde; pois, cerca de três dias antes que elas saem, fazem um tumultuoso murmúrio assim como um exército que se movimenta, o que, de forma verdadeira diz Virgílio: Podemos saber pelo som da multidão e de fato detê-las. Pois aquele som rouco marcial evocado em sintonia, e o som irregular da multidão imita uma trombeta (Col., Rust., 9, 9, 3-4). ${ }^{13}$

A agitação das abelhas, neste caso, é comparada a um exército que se movimenta antes da batalha, e o barulho produzido pela multidão da plebe, semelhante a um som ecoado pelos militares, era um indicador do início de novas turbulências que colocam em risco a ordem. Nesse sentido, a intervenção do apicultor, para Columela, é indispensável, pois, caso contrário, a ausência de uma supervisão das demandas tanto dos generais quanto do conselho dos anciãos acarretaria no surgimento de uma guerra civil:

Por isso o que tem que se fazer é ter o máximo de observação, quer elas saiam para a batalha, pois lutam como uma espécie de guerra civil entre si e como se fossem guerras estrangeiras com outros enxames, ou quando fogem, o apicultor deve estar pronto para qualquer evento. A batalha entre as abelhas de um mesmo enxame, que divergem entre si, ou entre dois enxames em desacordo, é facilmente contida; pois, como o mesmo poeta diz: Pacificá-las pressionando nelas uma pequena quantidade de pó (Col., Rust., 9, 9, 5-6). ${ }^{14}$

Assim, mesmo que a máxima observação e diligência do apicultor não consigam evitar as lutas no interior dos enxames, ou entre enxames, portanto inter e intra colmeias,

\footnotetext{
${ }^{13}$ No original: Quod ne fiat, boni curatoris est vernis temporibus observare alvos in octavam fere diei, post quam horam non temere se nova proripiunt agmina, eorumque egressus diligenter custodiat. Nam quaedam solent, cum subito evaserunt, sine cunctatione se proripere. Poterit exploratam fugam praesciscere vespertinis temporibus aurem singulis alveis admovendo. Siquidem fere ante triduum quam eruptionem facturae sunt, velut militaria signa moventium tumultus ac murmur exoritur, ex quo, ut verissime dicit Vergilius: corda licet vulgi praesciscere, namque morantis/Martius ille aeris rauci canor invocat, et vox/auditur fractos sonitus imitata tubarum.

${ }^{14}$ No original: Itaque maxime observari debent quae istud faciunt, ut sive ad pugnam eruperint (nam inter se tamquam civilibus bellis et cum alteris quasi cum exteris gentibus proeliantur), sive fugae causa se proripuerint, praesto sit ad utrumque casum paratus custos. Pugna quidem vel unius inter se dissidentis vel duorum examinum discordantium facile conpescitur; nam, ut idem ait, pulveris exigui iactu conpressa quiescit.
} 
configurando uma guerra civil (civilis bellum), ele (o apicultor) deve atentar para a utilização de recursos necessários para pacificá-las. Assim, retornariam à ordem e à manutenção da sociedade das abelhas.

Columela prescreve literalmente os métodos recomendados por Virgílio, o que revela uma proximidade entre dois autores sobre a necessidade de intervenção do apicultor para gerenciar os conflitos. Para Virgílio, é necessária a intervenção do apicultor como forma de evitar a descentralização do poder em vários reinos e a própria dissolução da colmeia: "Incólume é o rei, em todos há um só espírito, quando ele se perde, a fidelidade é quebrada, as próprias abelhas pegam o mel e a estrutura dos favos é dissolvida" (Verg., G., 4, 212-218). ${ }^{15}$

Dessa maneira, para Virgílio, a ênfase na intervenção do apicultor é, sobretudo, na concentração de poder em apenas um rei, eliminando os piores, para que, como citado literalmente por Columela, "o melhor na corte vácua reine" (Verg., G., 4, vv. 88-90). ${ }^{16} \mathrm{O}$ destaque da prescrição de Virgílio, sobre a necessidade de concentração do poder no interior da colmeia é significativo, uma vez que esta diverge de uma tradição anterior, sobretudo, em Aristóteles. Para Aristóteles, o número de rainhas não deve nem ser excessivo, nem centrado em apenas uma. Isso porque se, por um lado, um contingente elevado poderia elevar as discórdias internas, por outro lado, a existência de apenas uma rainha colocaria em risco a própria reprodução da colmeia (Arist., Hist. an., 4, 553b).

Nesse ponto, Columela se distancia das recomendações de Virgílio e se aproxima das de Aristóteles. Columela concorda com Virgílio que a guerra civil é prejudicial para a sociedade, mas ressalta que nem sempre o estabelecimento da paz é resultado da concentração de poder em apenas um rei. Pelo contrário, quando há o reconhecimento entre os príncipes, a paz também se restabelece:

Ou, então, aspergindo água com mel ou vinho de uvas-passas ou algum líquido semelhante, pois, o sabor doce, familiar entre elas, diminui a crueldade e a ira. Pois os mesmos expedientes reconciliam os reis discordantes. Muitas vezes há vários líderes de um povo, e a população é dividida em facções pelas sedições de seu chefe. Isso deve ser frequentemente proibido, uma vez que nações inteiras são destruídas pela guerra civil intestina. E assim, se há reconhecimento entre os príncipes, estabelece-se a paz incruenta. Se, entretanto, notá-las lutando batalhas, terá o cuidado de matar os líderes das facções; mas quando

\footnotetext{
${ }^{15}$ No original: Rege incolumi mens omnibus una est; / amisso rupere fidem constructaque mella / diripuere ipsae et crates solver favorum.

${ }^{16}$ No original: melior uacua sine regnet in aula. Leah Kronenberg (2009, p. 153-154) ressalta que, por um lado, embora a batalha das abelhas represente as motivações egoístas dos indivíduos que competem por seus próprios interesses, por outro lado esta batalha, no caso específico de Virgílio, pode ser compreendida também como uma utopia política em que o sacrifício de alguns indivíduos é realizado em prol de um bem coletivo. Assim, esta utopia política pode ser compreendida como uma forma de minimizar os danos da competição aristocrática do final da República, ou seja, como uma forma de enaltecer os resultados destes conflitos simbolizados pelo governo do imperador Augusto.
} 
eles continuam lutando, elas podem ser acalmadas pelos remédios acima mencionados. Em seguida, quando um enxame se estabeleceu em um ramo de um arbusto frondoso, deve-se observar se todo o enxame está dependurado como um cacho de uvas. Este será um sinal de que ou há apenas um rei, ou se são vários fielmente reconciliados, e assim deixe-os que voltem para sua morada. $\mathrm{Se}$, no entanto, o enxame é dividido em dois ou até mais aglomerado, você não precisa ter dúvida de que existem vários chefes e que eles ainda estão irados, e você terá que procurar os chefes nas partes mais aglomeradas onde você vê as abelhas mais intimamente amontoadas. (Col., Rust., 9, 9, 6-8). ${ }^{17}$

Nesse sentido, a intervenção do apicultor é necessária como uma forma de assegurar de que, na ausência de apenas um rei (rex), haja ao menos vários fielmente reconciliados. Se admitirmos que a função do apicultor, de forma metafórica, é semelhante àquela do Imperador em Roma, a imagem ideal que se depreende em Columela é de que, diante da ausência de um projeto coletivo coeso entre diferentes generais em ascensão, o Senado e a domus Caesaris, a figura do imperador se torna indispensável como forma de mediar os conflitos e tensões envolvendo as demandas individuais ou coletivas de cada um destes grupos.

Como ressalta Neville Morley (2007, p. 468), podemos "especular até que ponto as ideias de Columela sobre as relações entre príncipes - incluindo seu retorno à crença aristotélica de que era possível para eles coexistirem harmoniosamente - foram influenciados pelos desenvolvimentos reais pós-augustanos".

A participação de Columela nos conflitos entre o Império Romano e o Império Parta à época do principado de Nero pelo controle da Armênia pode ser uma chave interessante para compreender, por meio da metáfora, a forma como ele concebia o papel do apicultor-imperador no gerenciamento das tensões entre os generais romanos. De acordo com Tácito, a sexta legião, da qual Columela foi tribuno militar, ficou sob o comando de Corbulão, na Síria (Tácito, Annales, 15, 6, 3). Portanto, os conflitos na fronteira da província da Ásia merecem nosso destaque, pois nos permitem ampliar os significados da metáfora das abelhas no contexto do principado de Nero.

\footnotetext{
17 No original: aut aqua mulsea passove et alio quo liquore simplici respersa, videlicet familiari dulcedine saevientium iras mitigante. Nam eadem mire etiam dissidentis reges conciliant. Sunt enim saepe plures unius populi duces, et quasi procerum seditione plebs in partis diducitur, quod frequenter fieri prohibendum est, quoniam intestino bello totae gentes consumuntur. Itaque si constat principibus gratia, maneat pax incruenta. Sin autem saepius acie dimicantis notaveris, duces seditionum interficere curabis; dimicantium vero proelia praedictis remediis sedantur. Ac deinde cum agmen glomeratum in proximo frondentis arbusculae ramo consederit, animadvertito an totum examen in speciem unius uvae dependeat. Idque signum erit aut unum regem inesse aut certe plures bona fide reconciliatos, paterisque dum in suum revolet domicilium. Sin autem duobus aut etiam conpluribus velut uberibus ductum fuerit examen, ne dubitaveris et pluris proceres et adhuc iratos esse, atque in his partibus quibus maxime videris apes glomerari requirere duces debebis. Itaque suco praedictarum herbarum, id est melisphylli vel apiastri, manu inlita, ne ad tactum diffugiant, leviter inseres digitos, et diductas apes scrutaberis, donec auctorem pugnae reperias.
} 


\title{
A metáfora das abelhas: guerra e diplomacia sob o principado de Nero
}

A disputa pela hegemonia na Armênia não era, à época de Nero, uma novidade. Os conflitos entre romanos e partas pelo controle desta região remontam ao último século da República romana, marcando derrotas e vitórias para ambos os lados. No entanto, as hostilidades ficaram suspensas até o ano de 55, quando Vardanes se rebelou contra seu pai,Vologeses, reanimando os conflitos pelo controle da Armênia. Após a traição de seu filho, Vologeses voltou a reivindicar a região para seu irmão Tirídates. Contudo, os romanos viam naquela região uma clara oportunidade de ampliação e controle dos negócios no Oriente.

Considerando a metáfora das abelhas a partir do contexto no qual o De Re Rustica está inserido, Columela parece atento para o fato de que não era apenas a hegemonia romana que estava em risco na fronteira oriental de seu Império, mas também a estabilidade entre as diferentes instâncias do poder: o exército, o Senado e o próprio imperador. Daí a importância a ele concedida ao papel do apicultor-imperator como um ponto de equilíbrio entre as três esferas do poder. Esta preocupação é de suma importância para Columela, sobretudo, como relação ao processo de sucessão do poder:

\begin{abstract}
Há algumas pessoas que preferem remover o rei mais velho, mas isso é prejudicial; pois a multidão dos mais velhos, que formam uma espécie de Senado, parece não obedecer aos mais jovens, obstinadamente desprezando as ordens daqueles que são mais fortes, e são oprimidas por punições e mortes. Acontece que um enxame mais jovem, quando o rei das abelhas velhas, que temos deixado no poder, morre de velhice, como quando em uma família o senhor morre e, devido à excessiva liberalidade, os demais entram em discórdia, o que, no entanto, facilmente pode se corrigir. Pois, quando se tem vários generais um é eleito e é transladado para aqueles que estão sem governo, e é feito rei (Col., Rust., 9, 11, 2-3). ${ }^{18}$
\end{abstract}

Como aponta Aloys Winterling (2012, p. 10), "os obstáculos para matar o monarca se mostraram notavelmente baixos na Roma Antiga: dos doze imperadores do primeiro século d.C., apenas cinco morreram de morte natural". Como podemos notar, para Columela, os conflitos sociais no interior da colmeia, além de colocar em risco a sobrevivência das abelhas (cidadãos), coloca em risco a própria estabilidade do Estado. Contudo, diante de uma crise e necessidade de sucessão, o rei (rex) deve ser escolhido

\footnotetext{
${ }^{18}$ No original: Sunt qui seniorem potius regem summovent, quod est contrarium, quippe turba vetustior velut quidam senatus minoribus parere non cense[n]t, atque imperia validiorum contumaciter spernendo poenis ac mortibus afficitur. Illi quidem incommodo, quod iuveniori examini solet accidere, cum antiquarum apium relictus a nobis rex senectute defecit, et tamquam domino mortuo familia nimia licentia discordat, facile occurritur. Nam ex iis alvis quae plures habent principes dux unus eligitur, isque translatus ad eas quae sine imperio sunt rector constituitur.
} 
dentre os vários generais (duces). Sobre esta passagem do texto de Columela, Sam Van Overmeire (2012, p. 42) defende o seguinte argumento:

\begin{abstract}
O apicultor deve deixar o mais velho viver, senão parte das abelhas terá que tolerar um governante mais jovem. A morte de um velho soberano pode trazer o caos, mas um novo líder pode ser escolhido de um agrupamento onde existem vários. Isso também nos lembra de Roma no primeiro século: como velhos senadores, as abelhas mais velhas não gostavam de obedecer a um jovem soberano. A desordem após a morte do rei, e a escolha entre múltiplos candidatos, pode se referir a Roma também: é uma referência às guerras civis que surgiram após a morte de César, ou uma alusão à turbulência que se seguiu ao assassinato de Calígula?
\end{abstract}

Como destaca Sam Van Overmeire (2011), estas turbulências podem estar relacionadas tanto ao período das guerras civis após a morte César, quanto às agitações sociais decorrentes da morte de Calígula. Contudo, a nosso ver, o referencial de Columela parece mais próximo de sua realidade imperial. De acordo com Suetônio, a transição do governo de Calígula para Cláudio foi marcada por tumultos. Os cônsules, em conjunto com o Senado e as coortes pretorianas, ocuparam o fórum e o Capitólio dispostos a restaurar a liberdade republicana. Contudo, Suetônio relata que, devido à ausência de um comum acordo entre os aristocratas e as reivindicações da plebe para o anúncio de um novo imperador, permitiu-se que o exército jurasse fidelidade a Cláudio que, em troca, prometeu quinze mil sestércios a cada um, sendo a primeira vez que um imperador conquistava lealdade do exército mediante um pagamento (Suetônio, Diuus Claudius, 5, 10, 3-4). Estes eventos, de fato, corroboram a hipótese defendida por Sam Van Overmeire.

No entanto, a nosso ver, para além das hipóteses levantada por Sam Van Overmeire (2011), as prescrições de Columela também podem estar associadas à sucessão do governo de Cláudio por Nero, que ascendeu ao poder aos dezesseis anos, em 54. Tácito narra que, no decorrer do início das hostilidades entre romanos e partas, rumores começaram a circular na cidade questionando a (in)capacidade de Nero, um príncipe tão jovem, em decidir sobre os assuntos da guerra. As opiniões se dividiram. De um lado estavam aqueles que acreditavam na incapacidade de Nero devido a sua juventude e por ser governado por uma mulher, sua mãe Agripina, e por professores, Sêneca e Burro. Do outro lado, estavam os defensores da sabedoria de seus preceptores, alegando que a Res Publica estava melhor assegurada com a juventude de Nero do que com a velhice de Cláudio e que tanto Pompeu quanto Augusto demostraram, ainda que jovens, capacidade em conduzir as guerras civis. Além disso, Nero saberia ao menos escolher um general capaz de conduzir a guerra. Nero providenciou o recrutamento nas províncias e escolheu Corbulão como general (dux) responsável pela Armênia, o que foi recebido de forma positiva e festiva no Senado (Tac., Ann., 13, 6-8). Columela parece mais inclinado 
para o primeiro grupo, embora a escolha de Corbulão possa contar como um ponto positivo para Nero.

Essa discussão, no final do ano de 54, foi marcada pelo restabelecimento da ofensiva parta que depôs Radamisto, que estava sob o protetorado romano na província da Armênia. Para conter tais avanços, Tácito nos informa que as tropas romanas no Oriente foram dispostas sob o comando de dois generais: Umídio Quadrato e Cneu Domício Corbulão. Ambos os generais enviaram emissários para Vologeses, que reivindicava o trono da Armênia para seu irmão, Tirídates, para negociar um tratado de paz. Contudo, Vologeses, isentando-se da escolha de um dos generais para negociar o armistício, delegou tal função aos seus reféns, os enviados e os comissários que decidiram pelo nome de Corbulão. A discórdia entre os generais se acirrou, mas o imperador Nero, como forma de dirimir a intriga, declarou publicamente que a celebração dos sucessos das negociações se devia ao empenho tanto de Umídio quanto de Corbulão (Tac., Ann., 13, 8-9). Nero, neste contexto, adequa-se à imagem ideal de Columela, isto é, um mediador de tais tensões, que, em meio à ausência de um projeto coletivo coeso entre diferentes generais em ascensão, tornou a necessidade de um imperador indispensável como forma de mediar tais conflitos. Contudo, estes foram apenas os desdobramentos iniciais dos conflitos na fronteira oriental do Império.

Seguindo ainda a descrição de Tácito, Vologeses não concordava com a privação de um reino para o seu irmão, enquanto Corbulão não concordava em ceder as conquistas outrora de Lúculo e Pompeu. Diante das investidas partas, os romanos responderam e, sob o comando de Corbulão, sitiaram a capital da Armênia, Artaxata, e em seguida a cidade de Tigranocerta. Esta conquista foi comemorada pelo Senado que, por meio de um senatus consultum, coroou Nero como imperator. Em contrapartida, Nero nomeou para o governo da província da Armênia o jovem capadócio Tigranes, subserviente aos interesses romanos (Tac., Ann., 13, 34-41).

A partir de 62 os conflitos na fronteira oriental tomaram outra dimensão. Segundo Tácito, com o aumento das ofensivas partas, Corbulão, que estava responsável pela defesa na fronteira da Síria, solicitou um general auxiliar para o comando da Armênia. Nero enviou Cesônio Peto, que promoveu uma investida em direção ao monte Tauro, mas que foi duramente derrotada. Devido à fuga de seus legionários, Cesônio Peto se viu obrigado a solicitar o reforço das legiões de Corbulão. Embora, a rivalidade entre os generais fosse dissimulada, ela ficava cada vez mais evidente (Tac., Ann., 15, 8-13).

De acordo com Tácito, as ações de Cesônio Peto resultaram em vergonha, tanto para o próprio general, que fugiu deixando os mortos e feridos, quanto para os legionários fugitivos que, de forma desordenada, abandonavam a batalha. Por outro lado, 
o comportamento de Corbulão, ligado à sua capacidade diplomática em conduzir os conflitos, era enaltecido (Tac., Ann., 15, 15). Por fim, Cesônio Peto foi conduzido de volta a Roma enquanto Corbulão negociava o envio da embaixada parta a Roma que culminaria na coroação de Tirídates, que finalmente foi reconhecido como soberano na Armênia (Tac., Ann., 15, 24-31).

Seguindo os versos virgilianos, Columela deixa entrever que, na coexistência de vários generais, apenas o melhor deveria reinar, admitindo que, em casos de um mau governo, até mesmo o rei deveria ser destituído de seu trono:

Estes reis são um pouco maiores e mais alongados em forma do que as outras abelhas, com as pernas retas, mas de asas menos amplas, de uma cor brilhante, bela e suave, sem pelos e sem ferrão, a menos que alguém considera como ferrão um pelo grosso que cresce no ventre, no entanto, eles não infligem uma ferida. Alguns, também, são encontrados de uma cor escura e peluda, de cuja natureza desaprovará por sua aparência física.

Assim com as duas faces do rei, também é a plebe

Uma é brilhante e como ouro e áspera

Insigne e expressiva por suas escamas rutilantes

É por isso que este é especialmente aprovado, sendo maior; para o tipo inferior, como uma escarrada, é sujo como:

Um viajante que vem da estrada empoeirada e

Que cospe areia de sua boca ressecada.

E assim, o mesmo poeta diz,

Inglorioso arrasta sua pança repugnante

Portanto, todos os generais são baseados neste tipo,

Assolado pela morte, deixa-o, para que reine o melhor na corte vácua.

No entanto, ele também deve ser despojado de suas asas, quanto tentar fugir com seu enxame; pois, se nós tirarmos suas asas, mantemos o general errante como que com grilhões, que, privados dos recursos de voo, não viria a sair dos limites do seu reino, por essa razão, detido por sua própria população de vaguear por aí (Col., Rust., 9, 10, 1-3). ${ }^{19}$

A despeito da coexistência de vários generais, Columela admite a superioridade de alguns. Tácito, ao expor as diferentes ações dos generais no Oriente, "acaba demonstrando também uma preferência ao admitir que Corbulão poderia e deveria ter resolvido a

\footnotetext{
${ }^{19}$ No original: Sunt autem hi reges maiores paulo et oblongi magis quam ceterae apes, rectioribus cruribus, sed minus amplis pinnis, pulchricoloris et nitidi, levesque ac sine pilo, sine spiculo, nisiquis forte pleniorem quasi capillum quem in ventre gerunt aculeum putat, quo et ipso tamen ad nocendum non utuntur. Quidam etiam infusci atque hirsuti reperiuntur, quorum pro habitu damnabis ingenium: Nam duo sunt regum facies, duo corpora plebis. /Alter erit maculis auro squalentibus ardens / et rutilis clarus squamis insignis et ore. Atque hinc maxime probatur qui est melior, nam deterior, sordido sputo similis, tam foedus est: quam pulvere ab alto /cum venit et sicco terram spuit ore viator, / et, ut idem ait, / desidia latamque trahens inglorius alvum. /Omnes igitur duces notae deterioris / dede neci, melior vacua sine regnet in aula. / Qui tamen et ipse spoliandus est alis, ubi saepius cum examine suo conatur eruptione facta profugere. Nam velut quadam compede retinebimus erronem ducem detractis alis, qui fugae destitutus praesidio finem regni non audet excedere, propter quod ne ditionis quidem suae populo permittit longius evagari.
} 
ameaça causada pela reação parta à agressão de Tigranes em 61, antes da chegada de Peto" (DRINKWATER, 2017, p. 142).

No entanto, o posicionamento de Nero permanece isento. Além de ter nomeado Peto como auxiliar no Oriente, mesmo após este ser derrotado, preferiu abster-se de um julgamento, mantendo-se acima das intrigas entre os generais, isentando tanto Peto de uma punição, quanto conferindo excessiva glória a Corbulão. Sobre o comportamento de Nero com relação à ala militar, John Drinkwater (2017, p. 157) acrescenta que:

Não havia uma "grande estratégia" imperial para o Oriente ou para o Império como um todo. A administração concedeu a seus generais uma licença notável para conceber suas próprias estratégias e táticas regionais: como no caso de Suetônio Paulino na Grã-Bretanha, Emiliano ao redor do Mar Negro e, acima de tudo, Corbulão na Síria, que seguiu sua própria política apesar das decisões produzidas em Roma. O novo "lago romano" surgiu por acidente, não por projeto. Na verdade, embora o regime de Nero tenha pensado um pouco na administração das províncias, agindo contra funcionários imperiais corruptos, sua compreensão da situação política e militar mais ampla parece ter sido fraca.

É importante destacar que a completa transformação de Nero em inimigo somente se deu após longos quatorze anos no poder, o que mais uma vez reforça a ideia de que tal adjetivação se transforma, é cíclica e depende de diferentes avaliações de diferentes setores da sociedade. Por um lado, o comportamento de Nero diante das intrigas entre os generais romanos parece positiva, atuando apenas como um mediador de tais conflitos. Entretanto, a sua isenção em tomar decisões e partidos pode ter sido vista também de forma negativa.

Como mencionamos, ainda no início das hostilidades entre romanos e partas, havia certa tensão sobre como Nero iria conduzir a guerra. Embora a nomeação de certos generais possa ter sido vista de forma positiva, a ausência de Nero nos conflitos pesava sobre sua popularidade entre uma parcela dos setores militares. Ademais, a capacidade militar e diplomática de Corbulão o colocava em situação superior à do próprio imperador, que fez da gloria de seu general as suas próprias. Assim, ao mesmo tempo que é positiva a posição do imperator como um mediador dos conflitos entre os generais, a ausência do seu atributo militar gerava certo desconforto neste setor, "cujos comandantes viram o poder imperial aberto à disputa uma vez que a dinastia se esvaziara" (JOLY, 2020, p. 302).

\section{Conclusão}

Como observa Fábio Faversani (2014, p. 160), "as razões pelas quais alguém é considerado um bom ou um mau governante obedecem a certos aspectos gerais, mas 
também sofrem uma forte carga de conjunturas específicas, de quadros de interesses específicos." Portanto, a construção de certos modelos de comportamento ideal para o princeps mudava de acordo com atendimento ou não aos interesses de cada um dos grupos que competiam pelo acesso ao poder. Aloys Winterling $(2012$, p. 6) nos fornece uma síntese desta questão de forma bastante clara:

\begin{abstract}
Praticamente todos os relatos sobre os imperadores conhecidos por nós provêm de autores que eram membros da ordem senatorial ou equestre. O mesmo vale, sem dúvida, para aqueles autores, que hoje desconhecemos, das invectivas escritas com "ódio recente". Eles eram, portanto, os membros da sociedade aristocrática que - por exemplo, nas recepções na corte - estavam em contato direto e regular com os imperadores e que foram imediatamente afetados pelo comportamento imperial em suas oportunidades de vida - por patronato ou acusações. Assim, os retratos denunciatórios de Calígula, Nero e Domiciano não podem, de modo algum, ser tomados literalmente. Contudo, como tal, oferecem uma evidência valiosa e de primeira linha dos conflitos fundamentais entre esses imperadores e a elite aristocrática.
\end{abstract}

Decorrente de sua carreira militar, Columela provavelmente ingressou na ordem equestre, grupo que, cada vez mais, vinha ocupando espaços de prestígio na administração da res publica. Decerto, sua avaliação sobre a atuação do imperador estava sujeita ao atendimento dos interesses particulares de sua ordo, ou dos indivíduos aos quais ele estava ligado por relações de poder que escapavam da esfera institucional. Portanto, além da realidade material concreta das uillae, a sua experiência militar no Oriente pode ter influenciado a forma como ele projetava as relações entre os generais, os interesses do Senado e a atuação do imperador na administração destas diferentes demandas por meio da metáfora das abelhas.

Por um lado, as prescrições de Columela propõem que o apicultor deve atuar colocando-se acima dos conflitos das abelhas. Dessa forma, a coexistência de vários príncipes e/ou generais é vista de forma positiva. Por outro lado, isto não quer dizer que o apicultor devesse se ausentar de suas tarefas. Aliás, sua presença é um sinal de estabilidade e mediação entre as diferentes instâncias de poder. Desse modo, traduzido para o universo político e social, a ausência do imperador pode levar à autodestruição dos generais que, movidos por seus interesses individuais ou de grupo, colocavam em risco a estabilidade da res publica. Isto é, apesar de a concentração excessiva de poder nas mãos do imperador ser negativa, por outro lado, a presença deste é necessária para a própria sobrevivência do Estado, na medida em que ele atuava como um mediador de seus conflitos.

Buscamos, portanto, relacionar a metáfora das abelhas presente no texto de Columela com as tensões envolvendo os generais romanos e sua relação com o imperador e o Senado durante os conflitos entre o Império Romano e o Império Parta à época de Nero. 
Devido à presença de Columela no Oriente e considerando que a sexta legião, da qual ele foi tribuno, esteve sob o comando de Corbulão, a metáfora no De Re Rustica demonstra certa tensão entre a capacidade tática, militar e diplomática de um imperator ideal, em contraposição a uma imagem, que, ao nosso ver, estava relacionada ao imperador Nero, cuja ausência da habilidade militar fora avaliada de forma negativa.

\section{Referências}

\section{Documentação textual}

PLATÃO. A república. Tradução de Leonel Vallandro. Rio de Janeiro: Nova Fronteira, 2018. ARISTÓTELES. História dos animais: Livros I-VI. Tradução do grego de Maria de Fátima Sousa e Silva. Lisboa: Imprensa Nacional-Casa da Moeda, 2006.

CATO/VARRO. On Agriculture. Cambridge: Harvard University Press, 1979.

COLUMELLA. On Agriculture. Cambridge, Harvard University Press, 1977. 3 v. PLINY. Natural History. Cambridge: Harvard University Press, 1968. 8 v.

SÊNECA. Tratado Sobre a Clemência. In: BRAREN, I.; MENDONÇA, A. S. (org.). Salústio; Sêneca. Clássicos do Pensamento Político. Petrópolis: Editora Vozes, 1990.

SUETÔNIO. As vidas dos doze Césares. Tradução Sady Garibaldi. Rio de Janeiro: Ediouro, $\mathrm{s} / \mathrm{d}$.

TÁCITO. Anais. Tradução Leopoldo Pereira. Rio de Janeiro: Departamento de Imprensa Nacional. 1964.

VARRÃO. Das coisas do campo. Tradução de Matheus Trevizam. Campinas: Editora Unicamp, 2012.

VIRGIL. Eclogues, Georgics, Aeneid. Cambridge: Harvard University Press, 1916.

\section{Obras de referência}

GLARE, P. G. W. (ed.). Oxford Latin dictionary. Oxford: University Press, 1968.

HORNBLOWER, S.; SPAWFORTH, A.; EIDINOW, E. (ed.). The Oxford classical dictionary. Oxford: Oxford University Press, 2012.

\section{Obras de apoio}

ASH, H. Introduction. In: COLUMELLA. On Agriculture. Cambridge: Harvard University Press, 1960. $1 \mathrm{v}$. 
DRINKWATER, J. F. Nero: emperor and court. Cambridge: Cambridge University Press, 2019.

FAVERSANI, F. 'Ékphrasis' e as fronteiras da descrição em Tácito. Letras Clássica, v. 19, n. 1, p. 43-53, 2015.

FAVERSANI, F. 'Quinquennium Neronis' e a ideia de um bom governo. Phoînix, n. 20, v. 1, p. 158-177, 2014.

JOLY, F. D. Espaço, poder e escravidão no 'De Re Rustica' de Columela. Revista Brasileira de História, v. 23, n. 45, p. 281-299, 2003.

JOLY, F. D. Tácito e a metáfora da escravidão: um estudo de cultura política romana. São Paulo: Edusp, 2004.

JOLY, F. D. Nero: um artista no poder. In: REDE, M. (ed.). Vidas Antigas: ensaios biográficos da Antiguidade. São Paulo: Intermeios, 2020.

KNUST, J. E. M. Entre a literatura agrária latina e a economia rural romana: elementos discursivos e aspectos econômicos em Catão e Varrão. Aletheia, n. 1, p. 91-108, 2017.

KRONENBERG, L. Allegories of farming from Greece and Rome: philosophical satire in Xenophon, Varro, and Virgil. Cambridge: Cambridge University Press, 2009.

LAKOFF, G. Metaphors We Live By. Chicago: The University of Chicago Press, 1980.

MORLEY, N. Civil war and succession crisis in Roman beekeeping. Historia: Zeitschrift für Alte Geschichte, n. 4, p. 462-470, 2007.

NELSESTUEN, G. A. Varro the Agronomist: political philosophy, satire, and agriculture in the Late Republic. Columbus: Ohio State University Press, 2015.

REAY, B. Cato's De agri cultura and the spectacle of expertise. In: BECKER, J. A.; TERRENATO, N. (ed.). Roman Republican villas: architecture, context, and ideology. Ann Arbor: The University of Michigan Press, 2011.

SAILOR, D. Writing and empire in Tacitus. Cambridge: Cambridge University Press, 2008. TREVIZAM, M. Prosa técnica: Catão, Varrão, Vitrúvio e Columela. Campinas: Editora da Unicamp, 2014.

VAN OVERMEIRE, S. The perfect King Bee: visions of kingship in ancient antiquity. Akroterion, n. 56, p. 31-46, 2011.

WINTERLING, A. Loucura imperial na Roma antiga. História, v. 31, n. 1, p. 4-26, 2012. 